\title{
Spectrophotometric Determination of Lead in Environment Samples by Benzoic Acid Azo PhenylCalix[4]arene (BAPC)
}

\author{
Le Van Tan (Corresponding author) \\ Ho Chi Minh City University of Industry, Ho Chi Minh City, Viet Nam \\ 12 Nguyen Van Bao, Ward 4, Go Vap Disc., Ho Chi Minh city, Viet Nam \\ Tel: 84-8-38940390Ｅ-mail: tanhuaf@yahoo.com \\ Nguyen Thi Ngoc Le \\ Kon Tum of Pedagogical College, Kontum Province, Viet Nam \\ Tel: 84-905171134 E-mail:ngocle_cdsp_kt@yahoo.com.vn
}

The research is financed by DAAD (Germany)

\begin{abstract}
A new and selective spectrophotometric method for the determination of trace amounts of $\mathrm{Pb}$ (II) in aqueous environmental samples is reported. The interaction in solution between $\mathrm{Pb}$ (II) and Benzoic acid Azo Phenyl Calix [4] arene (BAPC, 1) was studied. Upon reaction of PABC and $\mathrm{Pb}(\mathrm{II})$ a stable complex is formed. Under the conditions reported here the method furnishes reproducible results with basic media. The calixarene derivative shows strong binding ability to $\mathrm{Pb}^{2+}$ ion with formation of a 1:1 complex. Beer's law is obeyed in the range of $2.0 \times 10^{-6}-2.4 \times 10^{-5}$ molL $^{-1}$ of $\mathrm{Pb}^{2+}$. The apparent molar absorptivity $(\varepsilon)$ of $1-\mathrm{Pb}^{2+}$ complex was $1.89 \times 10^{4}$ $\mathrm{Lmol}^{-1} \mathrm{~cm}^{-1}$ at $440 \mathrm{~nm}$, and the detection limit is $1.4 \times 10^{-6} \mathrm{~mol} \mathrm{~L}^{-1}$. The calixarene 1 showed high sensitivity and selectivity for $\mathrm{Pb}^{2+}$. The method was used to determine the content of $\mathrm{Pb}$ (II) in synthetic and natural samples.
\end{abstract}

Keywords: Spectrometry, Determination of lead traces, Water, Vegetable, Vetiver-grass, Azo-calixarene

\section{Introduction}

Lead is a cumulative poison that enters the body from lead water pipes, lead-based paints and leaded petrol (Renner, R. 1995). Presence of even traces of $\mathrm{Pb}(\mathrm{II})$ in environmental samples leads to environmental pollution and many fatal diseases including dysfunction of renal blood and neurological systems. $\mathrm{Pb}$ (II) easily deposits in blood, kidney, reproductive system, nervous system and brain, and acute lead poisoning can result in colic shock, severe anemia and irreversible brain damage. Lead compounds as antiknocking agents in automobile fuels cause air pollution.

The determination of trace amounts of lead is very important in the context of environmental monitoring. Atomic absorption and atomic emission spectrometry are used for routine trace analysis of lead, however a large number of spectrometric methods for determination of lead are reported to face interference due to the presence of several metal ions (Table 1) (Du, B. et. al 2002, Fargussion, J.1990, Ferreira, S. L. C. et.al 1991, Dutta, S. \& Das, A. K. 2007, Kiehei, U. et. al 2000, Mondal, B. C., Das, A. K. 2002, Dutta, S. \& Das, A. K. 2007). For this reason there is an ongoing search for new organic reagents for direct and rapid spectrophotometric determination of trace amounts of lead, especially in aqueous solutions.

The structure elucidation of Benzoic acid Azo Phenyl Calix[4]arene (BAPC) was reported in our previous papers (Kim, T. H. et. al 2007, Kim, T. H. et. al 2008). Based on these findings, this paper reports a spectrophotometric method with a new reagent for a simple, fast, and sensitive determination of $\mathrm{Pb}$ (II) traces without preconcentration. The formula of the BAPC reagent is shown in Fig. 1.

\section{Experimental}

\subsection{Reagents}

All chemicals were analytical reagent grade. Water was purified and distilled. A stock solution of $1\left(1.0 \times 10^{-3} \mathrm{~mol}\right.$ $\left.\mathrm{L}^{-1}\right)$ was prepared in MeCN. Lead perchlorate stock solution $\left(2.0 \times 10^{-2} \mathrm{~mol} \mathrm{~L}^{-1}\right)$ was prepared in water. The $\mathrm{Pb}^{2+}$ solution was diluted 10 and 100 times to give $2 \times 10^{-3} \mathrm{~mol} \mathrm{~L}^{-1}$ and $2 \times 10^{-4} \mathrm{~mol} \mathrm{~L}^{-1}$ solutions. A working standard solution of $\mathrm{Pb}^{2+}\left(2.0 \times 10^{-5} \mathrm{~mol} \mathrm{~L}^{-1}\right)$ was prepared from this stock solution by dilution with distilled water. 
$\mathrm{KCl}-\mathrm{NaOH}$ buffer solution $(\mathrm{pH}=12.5)$ was used. Aqueous solutions with 0.010 mol. $\mathrm{L}^{-1}$ concentrations of different cations were obtained by dissolving the appropriate substance in distilled water.

\subsection{Apparatus}

Absorption spectra were measured with a Varian-5000 UV-visible spectrophotometer (USA).

\subsection{Procedure}

The solutions to be studied were prepared in $10 \mathrm{~mL}$ volumetric flasks. Measured volumes of $\mathrm{Pb}(\mathrm{II})$ and organic reagent solutions were introduced in the flasks and they were filled up to the mark with $\mathrm{KCl}-\mathrm{NaOH}$ buffer solution $(\mathrm{pH}=12.5)$. Absorbance of each solution was measured against a corresponding blank reagent similarly prepared.

\subsection{Collection of water, Vetiver grass and soil samples}

Soil, water and vetiver grass samples were collected from points in Kontum province (Vietnam). Vetiver grass (scientific name Vetiveria zizanioides L.), a robust and easily propagating species capable of adapting to a wide range of climate and soil conditions, requires little care. Vetiver grass grows as bushes. The slabs are relatively hard and most leaves are at the base. With its dense roots Vetiver grass is able to absorb toxic minerals such as N, $\mathrm{P}, \mathrm{Al}, \mathrm{Mg}, \mathrm{Hg}, \mathrm{Cd}$ and $\mathrm{Pb}$ (Troung, P.N.V., Baker, D. 1998) from fertilizers and pesticides thus preventing pollution of soil and water. In addition, Vetiver grass also helps to increase the soil fertility by means of a natural moisturizing effect. The grass roots and its dense body will retain soil and mud on the surface. Stems, leaves and grass roots when buried in soil will break down to organic material, make the ground more soft and airy, thus improving the mechanical properties of soil (Ilker, A., \& Metin, T. \& Quirine, M. K. \& Avni, C. 2008).

Vetiver grass samples were collected carefully using a hand shovel to dig out the soil around the grass. The plants were pulled out carefully, ensuring that no part of the root was lost. The different grass samples were kept individually in properly labelled polyethylene bags. Soil samples were collected from the same point where the grass samples were uprooted. The soil samples were collected to a depth of $15 \mathrm{~cm}$ using a soil auger. The soil samples were kept in labelled polyethylene bags. One litter of water was collected for lead determination in water. Polypropylene bottles used for the water samples were previously rinsed with deionized water and $30 \% \mathrm{HNO}_{3}$. The samples were brought to the laboratory and kept in the fridge prior to analysis for lead.

\subsection{Sample preparation}

Each grass sample was separated into leaves, roots, and stems and dried in an oven at $50{ }^{\circ} \mathrm{C}$ for 8 hours. The dried plant samples were milled using a laboratory blender and kept for digestion. Unwanted materials such as stones, leaves and debris were removed from the soil samples by handpicking. The soil sample was further broken down into finer particles using a laboratory mortar and pestle. The soil samples were dried in an oven for 8 hours at $80^{\circ} \mathrm{C}$ (Douglas, C. B., Wolfgang, F. 1995).

\subsection{Sample digestion}

Plant sample digestion

Grass samples were digested following the method of Allen et al. $3 \mathrm{~g}$ of the milled plant sample were weighed into a conical flask using a digital weighing balance. $3 \mathrm{ml}$ of $60 \%$ hydrochloric acid and $10 \mathrm{ml}$ of $70 \%$ nitric acid were added to the weighed milled plant sample. The conical flask was then placed on a laboratory hot plate for digestion until the white fume evolving from the conical flask turned brown. The mixture was allowed to cool and then filtered through a Whitman's filter paper, leaving a whitish residue. The filtrate was then filled up to 25 $\mathrm{ml}$ with distilled water and stored for analysis.

Soil sample digestion

The same procedure for the digestion of plant sample was used according to the method of Allen et al.

\section{Results and Discussion}

\subsection{Absorbance spectra}

The spectrum recorded for a solution containing $\mathrm{Pb}(\mathrm{II})$ and organic reagent are presented in Fig.2(a). A chemical interaction between $\mathrm{Pb}(\mathrm{II})$ and organic reagent has occurred. The maximum absorption of the complex is located at $440 \mathrm{~nm}$.

\subsection{Influence of the $\mathrm{pH}$}

The effect of $\mathrm{pH}$ on the absorption efficiency is shown in Fig.2 (b), which indicates that high deposition efficiency was achieved at $\mathrm{pH} 12-13$. The maximum and constant absorbance of the complex is obtained in the $\mathrm{pH}$ range of 12.3-12.7, and a $\mathrm{pH}$ of 12.5 may thus be chosen for the following experiments. At $\mathrm{pH}=12.5$, the effects of four 
kinds of buffers on the absorbance were also examined. $\mathrm{KCl}-\mathrm{NaOH}$ buffer solution was chosen .

\subsection{Stoichiometry of the complex}

The effect of reagent concentration was examined by measuring the absorbance of the solution containing a known concentration of $\mathrm{Pb}(\mathrm{II})$ and different amounts of organic reagent. The spectrophotometric titration using a constant amount of organic reagent and variable concentration of $\mathrm{Pb}$ (II) as well as Job's method were also employed in order to establish the stoichiometry of the complex. The results indicate formation of a complex $\mathrm{Pb}(\mathrm{II}): \mathrm{PABC}=1: 1$.

\subsection{The stability constant}

The apparent stability constant of the complex was calculated from the data obtained using the mole ratio method. The value of the stability constant is: $6.2 \times 10^{4} \mathrm{~mol}^{-1} \mathrm{~L}$ for PBC. The value of stability constant obtained at $25 \pm 2{ }^{\circ} \mathrm{C}$ show a very stable complex for the corresponding stoichiometry. The absorbance of $1-\mathrm{Pb}^{2+}$ complex can reach maximum in 10 min and remain unchanged for at least $3 \mathrm{~h}$.

\subsection{Calibration curve}

Beer Lambert law is followed for $\mathrm{Pb}(\mathrm{II})$ concentration in the $2.0 \times 10^{-6}-2.4 \times 10^{-5} \mathrm{~mol} \mathrm{~L}^{-1}(\mathrm{r}=0.9997) \mathrm{of} \mathrm{Pb}^{2+}$. Absorbance $(A)=0.025 \times C\left(10^{-6} \mathrm{~mol} \mathrm{~L}^{-1}\right.$ of $\left.\mathrm{Pb}^{2+}\right)+0.021(\mathrm{n}=8, \mathrm{r}=0.99)$. The molar absorptivity coefficient $(\varepsilon)$ is $1.89 \times 10^{4} \mathrm{~L} \mathrm{~mol}^{-1} \mathrm{~cm}^{-1}$.

\subsection{Interferences}

The influence of other metal ions such as alkali, alkaline earth, or transition metal ions on the absorption was studied repeatedly with very high concentrations. Results showed that metal ions do not affect the spectrum of the complex. $\mathrm{Cu}(\mathrm{II}), \mathrm{Ca}(\mathrm{II}), \mathrm{Fe}(\mathrm{II}), \mathrm{Cr}(\mathrm{III}), \mathrm{Co}(\mathrm{II}), \mathrm{Ni}(\mathrm{II})$ have been found to interfere only if their concentration exceeds the lead concentration by a factor or 280-500.

\subsection{Determination of $\mathrm{Pb}(\mathrm{II})$ in natural samples}

The spectrophotometric method was applied to the determination of $\mathrm{Pb}$ (II) in water, soil and vertiver grass in Kontum province, VietNam. The comparison of results presented in Table 2 shows good agreements between the values determined by the proposed method and other methods.

\section{Conclusion}

The calixarene derivative BAPC forms a 1:1 complex with $\mathrm{Pb}^{2+}$ suitable for spectrophotometric determination of lead traces in aqueous solution. The optimum conditions for complex formation have been elucidated. The new reagent has been used to analyze samples of water, soil and Vetiver grass in Kontum province. The results showed that this method offers sensitivity comparable to that of the traditional reagents. Advantages of the proposed method are simplicity, rapidity and sensitivity without interference from other metal ions and without sample preconcentration.

\section{References}

Douglas, C. B., Wolfgang, F. (1995). Speciation of lead in environmental and biological samples. Pure \& Appl. Chem., Vol. 67, No. 4, pp. 615-648.

Du, B., Yang, J., Wei, Q. \& Chang, G. (2002). Spectrophotometric determination of trace amounts of lead in environmental water samples in the presence of mixed microemulsion. Anal Lett, 35 895-908.

Dutta, S. \& Das, A. K. (2007). Synthesis, characterization and application of a new chelating resin functionalized with ithiooxamide. J Appl Polym Sc, 103 2281-2285.

Fargussion, J. (1990). The Heavy Elements: Chemistry, Environmental Impact and Health Effect (Pergamon, Oxford)

Ferreira, S. L. C., Andrade, M. G. M., Lobo, I. \& Costa, A. C. S. (1991). 2-(2-Thiazolylazo)-p-cresol (TAC) as a reagent for the spectrophotometric determination of lead (II). Anal Lett, 24, 1675-1682

Guo, Y., Din, B., Liu, Y., Chang, X. \& Meng, S. (2004). Determination of lead using a new chromogenic reagent 2-(2-sulfo-4- acetylphenylazo)- 7-(2,4,6-trichlorophenylazo)- 1,8-dihydroxynaphthalene-3, 6-disulfonic acid, Microchim. Acta, 144 257-261.

Ilker, A., \& Metin, T. \& Quirine, M. K. \& Avni, C. (2008). Humic Acid Addition Enhances B and Pb Phytoextraction by Vetiver Grass (Vetiveria zizanioides (L.) Nash). Water Air Soil Pollut, 188:335-343

Kiehei, U., Toshiaki, I., Cheng K.L. (2000). Handbook of Analytical Reagents. CRC Press, pp.189-196 
Mondal, B. C., Das, A. K. (2002). Microwave-assisted synthesis of a new chelating resin containing 2-aminothiophenyl S-acetic acid and its application to the determination of lead, React Funct Polym, 53, 45-52.

Renner, R. (1995). Environ. Sci. Technol, 29, 256.

Kim, T. H., Kim, S. H., Tan, L. V., Seo, Y. J., Park, S. Y., Kim, H., Kim, J. S. (2007). Transition metal ion selective ortho-ester diazophenylcalix[4]arene. Talanta, 7, 1294 -1297.

Kim, T. H., Kim, S. H., Tan, L. V., Dong Y., Kim, H., Kim, J. S. (2008). Diazo-coupled calix[4]arenes for qualitative analytical screening of metal ions. Talanta, 74 1654-1658.

Troung, P.N.V., Baker, D. (1998). Vetiver grass for stabilization of acid sulfate soil, p.196-198. In Proceedings of Second National Conference on Acid Sulfate Soils, Coffs Harbour, Sydney.

Table 1. Comparision of Analytical Parameters for the Spectrophotometric Determination of Lead

\begin{tabular}{|c|c|c|c|}
\hline Reagent & $\lambda(\mathrm{nm})$ & $\begin{array}{l}\varepsilon_{\lambda} \times 10^{-4} \\
\left(\mathrm{~L} \cdot \mathrm{mol}^{-1} \mathrm{~cm}^{-1}\right)\end{array}$ & Remark \\
\hline 1-(2-Thiazoylazo)-2-naphthol & 575 & 3,6 & $\begin{array}{l}\text { Light-sensitive, Co, Zn, Fe, Mn } \\
\text { EDTA interfere }\end{array}$ \\
\hline Porphyrin compounds & 479 & 2,2 & $\mathrm{Cu}, \mathrm{Ni}, \mathrm{Mn}, \mathrm{Cd}, \mathrm{Ca}, \mathrm{Mg}, \mathrm{Zn}$ Fe interfere \\
\hline Diphenylthiocarbazone & 520 & 2,5 & Light-sensitive \\
\hline $\begin{array}{l}\text { Phenylazoformic acid } \\
\text { 2- phenylhydrazide }\end{array}$ & 525 & 7,2 & \\
\hline Xylenol orange & 580 & 2,3 & $\begin{array}{l}\text { Light-sensitive, } \mathrm{Hg} \mathrm{Zn,} \mathrm{Al,} \mathrm{Bi,} \mathrm{Ni,} \\
\text { Re interfere }\end{array}$ \\
\hline 2-(2-Thiazoylazo)-p-cresol & 650 & 2,1 & Ni, Co, Zn, Fe, Cd, Cu interfere \\
\hline 4-(2-Pyridylazo)- resorcinol & 520 & 4,3 & $\mathrm{Cd}, \mathrm{Ni}, \mathrm{Cu}, \mathrm{Co}, \mathrm{Ag}, \mathrm{Hg}, \mathrm{Zn}, \mathrm{Fe}$ interfere \\
\hline Arsenazo-TB & 620 & 1,8 & Light-sensitive, $T i$, Th seriously interfere \\
\hline Diethyl dithiocarbamat acid, & & & \\
\hline Diethylammonium salt & 435 & 1,3 & $\mathrm{Cu}, \mathrm{Hg}, \mathrm{Zn}, \mathrm{Fe}$ interfere \\
\hline Arsenazo.III & 660 & 3,0 & $\mathrm{Al}, \mathrm{Cu}, \mathrm{Th} \mathrm{Ti}, \mathrm{U}$ Fe interfere \\
\hline 1 ( This work) & 440 & 1.2 & $\mathrm{Cu}, \mathrm{Ca}, \mathrm{Fe}, \mathrm{Cr}, \mathrm{Co}, \mathrm{Ni}$ interfere \\
\hline
\end{tabular}


Table 2. Determination of Lead in environment samples $(\mathrm{mg} / \mathrm{kg}) \mathrm{n}=5$

\begin{tabular}{|lll|}
\hline Samples & $\begin{array}{l}\text { Found by proposed } \\
\text { method }(\mathrm{mg} / \mathrm{kg})\end{array}$ & $\begin{array}{l}\text { Found by other method } \\
(\mathrm{mg} / \mathrm{kg})\end{array}$ \\
\hline W35 & $2.32 \pm 0.09$ & $\mathbf{2 . 2 1}$ - EPA-method 200.7 \\
W39 & $1.85 \pm 0.04$ & 1.98 - EPA-method 200.7 \\
W41 & $2.12 \pm 0.10$ & 2.03 - EPA-method 200.7 \\
W42 & $1.89 \pm 0.05$ & 2.04 - EPA-method 200.7 \\
W52 & $4.03 \pm 0.08$ & 3.90 - EPA-method 200.7 \\
S2 & - & - - AAS-Tome II \\
S160 & $2.14 \pm 0.12$ & 2.08 - AAS-Tome II \\
S68 & $2.52 \pm 0.08$ & 2.40 - AAS-Tome II \\
S10 & $1.32 \pm 0.10$ & 1.22 - AAS-Tome II \\
VG 21 & $0.75 \pm 0.07$ & 0.68 - AOAC 985.01 \\
VG36 & $1.25 \pm 0.06$ & 1.12 - AOAC 985.01 \\
VG47 & $1.18 \pm 0.07$ & 1.15 - AOAC 985.01 \\
VG53 & $0.98 \pm 0.05$ & 0.94 - AOAC 985.01 \\
\hline
\end{tabular}

* W: water, VG: Vetiver grass, S: soil, Number is place

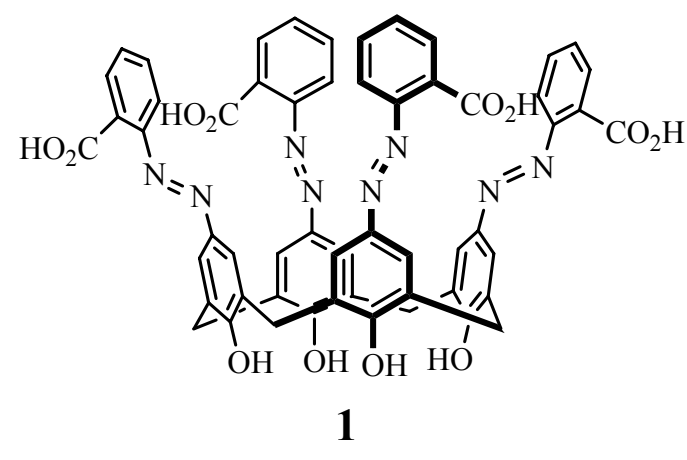

Figure 1. Structure of Benzoic acid Azo Phenyl Calix[4]arene (BAPC)
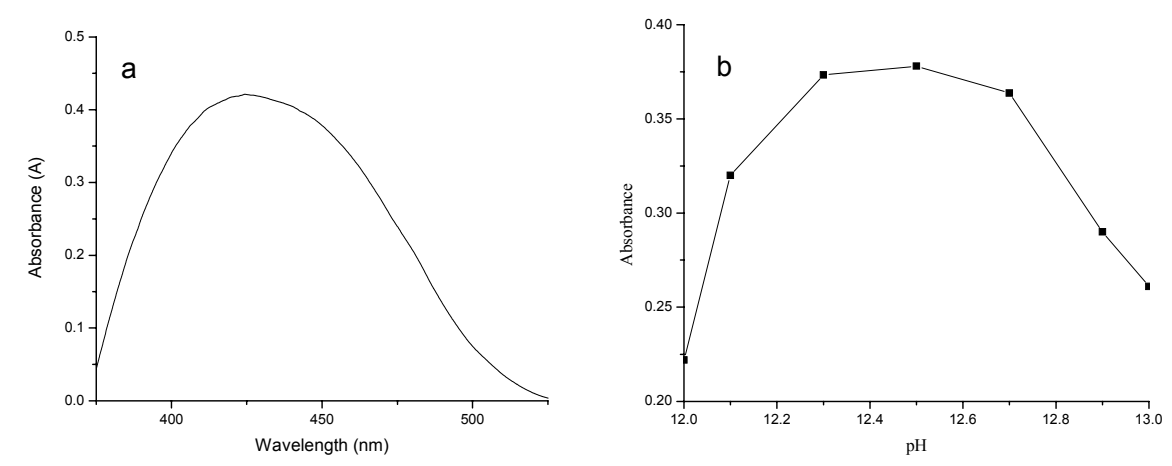

Figure 2. Absorption spectra of $\mathbf{2}$ and its $\mathrm{Pb}^{2+}$ complex at $\mathrm{pH} 12.5$ (a) Effect of $\mathrm{pH}$ (b) 